\title{
A RELIGIOSIDADE DO ASSISTENTE SOCIAL
}

\author{
Regiane Renata de Souza \\ Orientador(a): Claudia Neves da Silva
}

\section{RESUMO}

O presente trabalho tem como temática a presença e a influência de valores e princípios religiosos nos assistentes sociais da cidade de Londrina e região, especificamente em sua intervenção profissional, e surge devido à percepção da significativa influência que a religião ainda exerce nos indivíduos, e que algumas vezes determina tanto o comportamento quanto as ações dos mesmos. O objetivo é investigar como esses profissionais relacionam a religião, a religiosidade, com a prática profissional no ambiente de trabalho. Para tanto, é necessário buscar o contexto histórico da profissão no país e chegar a seu estado atual. Focando nas particularidades desses profissionais, é importante apresentar aspectos da subjetividade, uma vez que, o assistente social está inserido em um complexo problemático e controverso, que requer habilidades, dentre elas, a habilidade política - a ação para com o Estado - e a habilidade afetiva para trabalhar com as desigualdades e vulnerabilidades diárias do público que atende. A principal técnica de coleta de dados é o questionário aplicado para 130 assistentes sociais. Sua análise permite visualizar como a maioria dos assistentes sociais desenvolve o vínculo com a religião e/ou com os princípios religiosos no exercício da profissão, através de orações, por exemplo.

\section{INTRODUÇÃO}

$\mathrm{O}$ artigo pretende discutir a presença e a influência de valores e princípios religiosos na prática profissional do assistente social ${ }^{1}$. O interesse por esta temática justifica-se por constatar a influência que a religião ainda hoje exerce nos campos social, político e econômico, determinando por vezes, tanto a concpeção de mundo como o comportamento de homens e mulheres, fato que pudemos analisar em pesquisa realizada junto aos jovens que participam de manifestações religiosas ${ }^{2}$.

Uma pesquisa com os profissionais do Serviço Social vem sendo realizada desde $2014^{3}$ e o presente artigo traz alguns resultados fruto das seguintes indagações ${ }^{4}$ : diante do agravamento dos problemas sociais e da falta de recursos, o profissional do Serviço Social estaria se utilizando de valores como solidariedade e fraternidade para

\footnotetext{
${ }^{1}$ Para facilitar a leitura, faremos uso somente do artigo masculino quando nos referirmos ao profissional do serviço social.

${ }^{2}$ Projeto de Pesquisa: "Manifestações Culturais: Religião, Religiosidade e Juventude no Movimento Pentecostal", em que participei como bolsista de Inciação Científica entre os anos e 2012 e 2013.

${ }^{3}$ Questão social e religião: possíveis implicações na prática profissional do Assistente Social https://www.sistemasweb.uel.br/system/prj/pes/pdf/pes_pesquisa_09296.pdf

${ }^{4}$ SOUZA, Regiane Renata. A Presença da Religião e de Valores e Princípios Religiosos no Exercício Profissional do Assistente Social. 2016. 74 f. Trabalho de Conclusão de Curso (Graduação em Serviço Social) - Universidade Estadual de Londrina, Londrina, 2016.
} 


\section{SEMINÁRIO DE PESQUISA EM CIÊNCIAS HUMANAS - SEPECH \\ Humanidades, Estado e desafios didático-científicos \\ Londrina, 27 a 29 de julho de 2016}

enfrentar os problemas em seu cotidiano profissional? Seu pertencimento religioso interfere na intervenção profissional e reforçam preconceitos em seu cotidiano de trabalho?

Para a concretização da pesquisa, aplicamos um questionário a 104 assistentes sociais das cidades localizadas na região norte do Paraná, que participaram de um evento promovido pelo Departamento de Serviço Social da UEL e por visita ao local de trabalho do profissional. Não citaremos as cidades para evitar a identificação destes profissionais.

\section{SERVIÇO SOCIAL, SUBJETIVIDADE E RELIGIÃO}

Os múltiplos problemas que afloraram com o nascimento do capitalismo dividiu a sociedade em classes e colocou em evidência as desigualdades sociais, e à medida que estas se desenvolveram (e se desenvolvem) necessitaram (e necessitam) da intervenção do serviço social para dar respostas à sociedade e, principalmente ao capital.

Em linhas gerais, necessitou-se do serviço social como profissão quando as desigualdades começaram a ficar em evidência, quando a classe trabalhadora passou a reivindicar melhores condições de trabalho e de vida, deixando em evidência os problemas sociais e consequentemente, as desigualdades. Para que houvesse um controle, o Estado gerou o serviço social enquanto profissão, para dar conta das emergências sociais da época - décadas de 1930 e 1940 (IAMAMOTO, 1983). E ainda hoje trabalha nas situações sociais limites.

Profissional que em sua rotina de trabalho se depara com diversos problemas: pessoas que se encontram em situação de vulnerabilidade social, sem moradia própria, com a saúde precária, o limitado acesso às políticas sociais, vítimas de violência física, sexual, emocional, desempregados.

A partir da intervenção do assistente social nessas questões é que se pretende discutir a subjetividade, focada na terceira atividade imaterial, definida por Negri e Hardt (2001), "que envolve a produção e a manipulação de afetos e requer contato humano (virtual ou real), bem como o trabalho do tipo físico". (NEGRI; HARDT, 2001, p. 314 apud MANSANO 2010, p.36).

Antes de aprofundar este aspecto, cabe ressaltar que a atividade imaterial se caracteriza não de forma exclusiva através da exploração da forma física, refere-se aqui a ser um produto cultural, um serviço como a saúde, a educação, dentre outras. Mansano (2009) afirma que a categoria "atividade imaterial" retrata um grupo de atividades próximas, antes mencionado como prestação de serviços.

Em cada situação, o profissional busca agir de acordo com as particularidades do usuário; e de modo geral, precisa saber se relacionar com a população atendida. $\mathrm{O}$ contato social é a base do trabalho de tipo afetivo, no qual está inserido o assistente social; é importante mantê-lo em todos os atendimentos, uma vez que interfere na qualidade e nos resultados dos serviços prestados.

Durante a intervenção profissional, intrínseco ao corpo, está a afetividade e para além da intervenção, tal atividade encontra-se presente também em todos os aspectos da vida do ser social. O profissional do Serviço Social que mantém constante contato social, dificilmente conseguiria impor uma separação de sentimentos entre os 


\section{SEMINÁRIO DE PESQUISA EM CIÊNCIAS HUMANAS - SEPECH \\ Humanidades, Estado e desafios didático-científicos \\ Londrina, 27 a 29 de julho de 2016}

aspectos extremamente profissionais, separados do que é pessoal, enquanto vida fora do trabalho e seus respectivos modos de agir, pensar e sentir (MANSANO, 2010).

$\mathrm{O}$ assistente social está inserido em um complexo problemático e controverso, que requer várias habilidades, dentre elas, a habilidade política em sua a ação para com o Estado, e a habilidade afetiva para trabalhar com as desigualdades e vulnerabilidades diárias do público que atende. As relações de trabalho expressam consequentemente, relações de poder e a subjetividade também está presente.

Falar em subjetividade é falar em algo singular, pois a consciência é individual, cada ser tem sua particularidade mesmo que haja semelhança entre alguns. Refere-se à produção do significado do real que compõe o domínio do que é emocional, psíquico, afetivo do indivíduo ou da coletividade (FARIA; MENEGHETTI, 2001, p. 1).

O desrespeito à vida, aos objetos materiais de cada ser, a fome, as leis, e a falta delas, os valores de cada grupo social, as enfermidades, os preconceitos, as contradições entre as classes, estão dentro do trabalho do assistente social que ao não conseguir respostas, pode também sofrer.

Sendo grande o risco que corre o assistente social de se frustrar, de adoecer, qual via pessoal ele busca para continuar trabalhando com uma série de dificuldades todos os dias?

Ao ter que intervir em situações que envolvem vulnerabilidade física e material, mas não é possível atender, o profissional do Serviço Social pode afetar-se emocionalmente e ver-se diante do risco de voltar-se para outros recursos que não os institucionais e legais para atuar junto aos usuários das políticas sociais ou na relação com a equipe de trabalho.

O trabalho imaterial envolve interação e cooperação. Independente de sua área, o assistente social atua em equipe, em parcerias, em rede, não atua sozinho, é trabalhador assalariado, não detém os meios necessários para realizar suas atividades de forma autônoma (IAMAMOTO, 2013) e mesmo se tivesse, não deixaria de estar sujeito às dificuldades, aos limites, aos erros, e principalmente, às relações sociais que estabelece em diferentes espaços.

\section{CONCILIANDO PRÁTICA PROFISSIONAL E RELIGIÃO}

Os dados coletados nos permitiu analisar como os assistentes sociais da cidade de Londrina e região relacionam sua religião e religiosidade com a prática profissional, tanto ao lidar com outros profissionais, quanto ao intervir junto aos usuários das políticas sociais públicas.

Foram respondidos 130 questionários. Porém, para o universo de nossa análise, serão contabilizados 104 questionários, pois 26 questionários chegaram após o início de nossa análise. As assistentes sociais serão identificadas por letras, resguardando a identidade das mesmas.

A maioria dos profissionais que respondeu ao questionário é constituída por mulher, está entre os 35 e 45 anos de idade e concluiu o curso entre os anos de 2001 e 2013.

A área de atuação dos assistentes sociais é diversa: saúde, assistência social, habitação, educação e instituições sociais, públicas e privadas. Como o questionário foi aplicado em um evento sobre política de assistência social realizada na Universidade 


\section{SEMINÁRIO DE PESQUISA EM CIÊNCIAS HUMANAS - SEPECH \\ Humanidades, Estado e desafios didático-científicos \\ Londrina, 27 a 29 de julho de 2016}

Estadual de Londrina, em abril de 2014, a maior concentração ficou nesta política pública, como podemos constatar na tabela abaixo:

\section{Área de Atuação}

Assistência Social

Educação

Habitação

Não atua

Organizacional

Outra opção

Saúde

Várias opções

Tabela 1: Área de atuação

Fonte: Questionário aplicado aos assistentes sociais entre os anos de 2014 e 2015.

Foi perguntado aos assistentes sociais se frequentam algum um espaço religioso - igreja, centro espírita, terreiro de umbanda, candomblé:

\section{Frequenta espaço religioso?}

Sim

Não

Tabela 2: Espaço religioso frequentado

Fonte: Questionário aplicado aos assistentes sociais entre os anos de 2014 e 2015.

A seguir, foi perguntado o nome desse espaço. Seguindo o que já foi demonstrado pelo Censo de 2010, a maioria se declara da Igreja Católica, seguido das Igrejas Evangélicas.

Denominaremos genericamente por Igrejas Evangélicas, em virtude da diversidade de igrejas de matriz protestante entre os estudantes, decidi por denominar genericamente por Igreja Evangélica, haja vista que as diferenças na doutrina religiosa das mesmas não são profundas ${ }^{5}$.

\begin{tabular}{|l|l|}
\hline Denominação & Assistente (s) Social (is) \\
\hline Igreja católica & 60 \\
\hline Igreja evangélica & 20 \\
\hline Centro Espírita & 6 \\
\hline Candomblé & 1 \\
\hline
\end{tabular}

\footnotetext{
${ }^{5}$ Metodista, Presbiteriana, Assembleia de Deus, Brasil para Cristo, Comunidade Nova Aliança. Congregação Cristã no Brasil.
} 


\section{SEMINÁRIO DE PESQUISA EM CIÊNCIAS HUMANAS - SEPECH \\ Humanidades, Estado e desafios didático-científicos \\ Londrina, 27 a 29 de julho de 2016}

Não responderam

2

Tabela 3: Espaço religioso que frequenta

Fonte: Questionário aplicado aos assistentes sociais entre os anos de 2014 e 2015.

De um total de 89 pessoas que frequentam espaços religiosos, 75\%, responderam que a vida mudou ao frequentar um espaço religioso (Gráfico 4).

\begin{tabular}{|l|l|}
\hline Sua vida mudou? & Assistente (s) Social (is) \\
\hline Sim & 67 \\
\hline Não & 16 \\
\hline Não responderam & 6 \\
\hline
\end{tabular}

Tabela 4: Sua vida mudou

Fonte: Questionário aplicado aos assistentes sociais entre os anos de 2014 e 2015.

Os assistentes sociais informaram que precisam buscar a Deus e se firmarem na fé para conseguirem enfrentar as dificuldades do cotidiano. Essa necessidade de busca acontece, segundo as respostas escritas dos assistentes sociais, porque sempre há um problema pessoal, como a falta de compreensão e valorização da família e/ou de alguma doença:

Segundo Portella (2006, p.7) "as pessoas contemporâneas buscam, na seletividade de suas escolhas religiosas, de suas bricolagens e ressignificações, comporem para si um mundo com algum sentido", já que torna-se cada vez mais difícil enfrentar os embates cotidianos.

A vida centrada no presente, abreviada ao aqui e agora, a fluidez, a agilidade de tudo, a ilusão dada pelo capital, as necessidades e principalmente as vontades, incentivam o individualismo e as novas formas de comportamento, que retratam ao mesmo tempo, além da coragem, a insegurança e o medo e frente a uma diversidade de situações, também se encontram os direitos negados - à educação, à saúde, à assistência, e ao ter o básico necessário para viver - ou permitidos com base em critérios, e na face dos problemas sociais absolutamente expostos, ocorre uma busca pelo assistente social, que lida com dificuldades variadas diariamente, que mantêm e precisa manter um contato social, contato que gera e "pressupõe o acolhimento da presença viva do outro, que comparece na relação profissional expondo suas diferenças, expectativas, limites e potencialidades". (MANSANO, 2010, p. 38).

Portanto, mesmo que o assistente social seja um profissional e aja como tal, também tem uma vida além do trabalho, se relaciona com amigos, vizinhos e parentes, sofre ao enfrentar seus problemas pessoais, os problemas profissionais, que o atacam em seu aspecto psicológico, causando muitas vezes, a necessidade de buscar variados caminhos, como remédios, drogas e/ou a fé em uma divindade.

Firmam-se na fé, porque através dela encontram respostas para lidar com as diferentes situações do cotidiano profissional, conforme escreveu uma Assistente Social no questionário:

[A.S. P] Aumento da espiritualidade e tranquilidade para lidar com os embates do cotidiano. 


\section{SEMINÁRIO DE PESQUISA EM CIÊNCIAS HUMANAS - SEPECH \\ Humanidades, Estado e desafios didático-científicos \\ Londrina, 27 a 29 de julho de 2016}

Os profissionais de serviço social fazem parte de um grupo de trabalhadores assalariados que atuam em diferentes áreas com diferentes problemas sociais que surgem a partir do crescimento da população e da dificuldade política de administrá-lo, que gera demandas e situações diversas.

Como podemos perceber, o profissional do Serviço Social se vê em dois lados opostos, se por um lado, trabalha na implementação das políticas sociais, e, com isto, representando o Estado; por outro, está em contato diário com a usuária dos serviços sociais. Neste sentido, também acaba por intervir em situações que vão além das carências materiais. Como destacou Mansano (2010, p. 40): “À medida que esse trabalhador atua em questões que são de cunho afetivo, ele também participa da produção de subjetividades".

A população com a qual o assistente social mantém contato tem problemas reais e muitas vezes esses problemas não são solucionados pelo aparato legal, pelos representantes do Estado ou pelo próprio Estado (MANSANO, 2010). Há contrastes entre esses universos e mesmo que o assistente social deva agir como profissional, não há possibilidade de ser neutro diante do que lhe é posto.

Os assistentes sociais informaram que a fé, o querer ajudar, praticar a caridade, o assistencialismo não são forças propulsoras na escolha do curso; porém, algumas assistentes sociais escreveram que a crença lhes traz um olhar diferenciado diante das dificuldades:

[A.S. E] Tenho maior fé diante das dificuldades;

[A.S. F] Ressignificou a minha vida espiritual, deu um novo sentido a ela;

No que se refere a questão de "relacionar aspectos de trabalho com a espiritualidade", as respostas apresentam uma significativa ligação com a religiosidade, destacando o vínculo estabelecido entre religião/religiosidade e a influência da(s) mesma(s) na intervenção profissional do assistente social. Através das respostas escritas pudemos verificar como se dá esta relação:

[A.S. A] Nas relações do dia-a-dia de uma forma ecumênica;

[A.S. H] Na leitura de conjuntura;

[A.S. I] Serenidade para conduzir situação competitiva no relacionamento profissional;

[A.S. X] Na busca de amar as pessoas que atendo e com quem tenho diferenças

Encontram-se aqui as relações com o plano sagrado. É possível verificar que os assistentes sociais ao realizarem suas atividades profissionais, quando entram em contato com os usuários das políticas públicas e seus problemas e consequentemente produzirem e reproduzirem afetos (que estão intrínsecos às relações sociais), se veem diante da necessidade de ter fé em uma força superior que os fazem enfrentar e suportar as adversidades dos usuários e se relacionarem com a equipe de trabalho. 


\section{SEMINÁRIO DE PESQUISA EM CIÊNCIAS HUMANAS - SEPECH \\ Humanidades, Estado e desafios didático-científicos \\ Londrina, 27 a 29 de julho de 2016}

A calma, a paciência, a "luz" que precisam para encontrar respostas que não encontram em outras instâncias, como a ciência. $\mathrm{O}$ que pertence ao campo sagrado não está dado, não é palpável, não se coloca à prova e só será possível ser ou não (re) conhecido após a morte.

Ter uma crença e valores religiosos não se constituem em problema. O que gera conflitos é quando essas crenças e valores são considerados verdades absolutas, levando a conflitos e intolerância.

A Constituição Federal, em seu art. 5\%, inciso VI assegura a todos o livre exercício dos cultos religiosos e garante perante a lei, a proteção aos locais de culto e às suas liturgias. É dever de todos respeitar os valores de cada indivíduo.

O Código de Ética do Assistente Social também orienta à educação e ao respeito.

\section{TÍTULO III DAS RELAÇÕES PROFISSIONAIS CAPÍTULO I \\ Das Relações com os/as Usuários/as}

Art. $5^{\circ}$ São deveres do/a assistente social nas suas relações com os/as usuários/as:

b- garantir a plena informação e discussão sobre as possibilidades e consequências das situações apresentadas, respeitando democraticamente as decisões dos/as usuários/as, mesmo que sejam contrárias aos valores e às crenças individuais dos/as profissionais, resguardados os princípios deste Código. (1993, p. 29).

Considera-se dever do assistente social, respeitar e acatar as determinações do Código de Ética. Assim, ele estará respeitando e não impondo aos usuários e à equipe o que acredita ser a única verdade.

\section{CONSIDERAÇÕES FINAIS}

A partir da análise dos dados da pesquisa, fica difícil contestar que a presença de valores e princípios religiosos ainda é significativa entre alguns profissionais do serviço social durante sua atividade profissional. $O$ trabalho deste profissional requer cautela, tanto em relação aos usuários, como para si mesmos, uma vez que atua em dois lados opostos, pois luta - perante o Código de Ética - pela defesa de direitos e é empregado pelo Estado, que não está sempre disposto a efetivar tais direitos.

O profissional que agrega à sua intervenção seus valores pessoais, suas crenças religiosas, poderá interferir no âmbito profissional e dificultar o exercício profissional, uma vez que o usuário também tem seus valores e crenças e estas, muitas vezes se diferem das dos profissionais. 


\section{SEMINÁRIO DE PESQUISA EM CIÊNCIAS HUMANAS - SEPECH \\ Humanidades, Estado e desafios didático-científicos \\ Londrina, 27 a 29 de julho de 2016}

\section{REFERÊNCIAS}

FREUD, Sigmund. O Futuro de uma Ilusão. 1990. Disponível em: $<$ http://portalgens.com.br/filosofia/textos/o_futuro_de_uma_ilusao_freud.pdf $>$. Acesso em: 20 dezembro 2015.

LANZA, Fabio; SILVA, Claudia Neves da. Manifestações Culturais Contemporâneas: A Participação de Jovens em Movimentos Religiosos de Natureza Pentecostal. Lisboa, 2012. Disponível em: $<$ http://www.aps.pt/vii_congresso/?area $=016 \&$ seccao $=$ SEC4e775972826ed\&mesa $=$ SEC4fb515430d5df>. Acesso em: 07 janeiro 2016.

MANSANO. Sônia Vargas. Dimensões afetivas atualizadas no trabalho do Assistente Social. Serviço Social em Revista. Londrina, v. 12, n. 2, p. 33-49, jan/jun. 2010.

Transformações da Subjetividade no Exercício do Trabalho Imaterial. Estudos e Pesquisas em Psicologia. Rio de Janeiro, v.9, n.2, p. 512-524, jun 2009.

NETTO, José Paulo. A Construção do Projeto Ético-Político do Serviço Social. Rio de Janeiro, 1999, p. 22.

Ditadura e serviço social: uma análise do Serviço Social no Brasil pós-64. 7. ed. - São Paulo: Cortez, 1998.

O movimento de reconceituação - 40 anos depois. In: Serviço Social e Sociedade, São Paulo, nº 84, p. 5-20, Nov. 2005.

NEVES, José Luís. Pesquisa qualitativa - Características, uso e possibilidades. São Paulo, 1996.

SIMÕES NETO, José Pedro. Assistentes Sociais e Religião: um estudo Brasil/Inglaterra. São Paulo: Cortez, 2005. 